\title{
Thrombus on the Device Early After the Procedure of the Left Atrial Appendage Closure with the Amplatzer Cardiac Plug: Is Something Wrong with the Procedure or the Device?
}

\author{
Baris Kilicaslan, Oner Ozdogan, Ali Kemal Cabuk, Inan Mutlu \\ Department of Cardiology, S.B.U Izmir Tepecik Research Hospital, Izmir, Turkey \\ ORCID: \\ Baris Kilicaslan: https://orcid.org/0000000315037554 \\ Oner Ozdogan: https://orcid.org/0000000332056917 \\ Ali Kemal Cabuk: https://orcid.org/0000000155493744 \\ Inan Mutlu: https://orcid.org/00000300717813
}

\section{Abstract}

Percutaneous left atrial appendage (LAA) closure is a currently utilized procedure for the prophylaxis of thromboembolic cerebrovascular events in selected patients with nonvalvular atrial fibrillation. The presence of thrombus on closure device was reported at $1^{\text {st }}$ and $3^{\text {rd }}$ months after the procedure, but as far as our knowledge, there are no data about early thrombus formation on the device during procedure. We present a case demonstrating thrombus on the atrial side of the Amplatzer Amulet LAA occluder device early after the implantation.

Keywords: Atrial fibrillation, sol atrial appendage, stroke

\section{INTRODUCTION}

Today, with an aging population, atrial fibrillation (AF) is more common and has an increased risk of embolic cerebrovascular accidents. Anticoagulation strategies alone are not sufficient, and as a large proportion of the thrombus involved in these cerebrovascular accidents are seen to arise from the left atrial appendage (LAA). Device closure of the LAA is a nonpharmacologic approach to stroke prevention in AF patients. We present a case with an early thrombotic complication during LAA closure which was successfully treated.

\section{Case Report}

A physically active 76-year-old female with persistent AF was referred for the LAA occlusion because of recurrent

Submission: 22-Dec-18 Revision: 18-Jan-19 Accepted: 23-Apr-19

\begin{tabular}{|l|l|}
\hline \multicolumn{2}{c|}{ Access this article online } \\
\hline Quick Response Code: & Website: \\
& \\
http://www.ijcva.com
\end{tabular}

cerebral stroke, under anticoagulant therapy with warfarin and afterward with dabigatran $150 \mathrm{mg}$ bid. The patient's CHADS-VASc score was 5 and HAS-BLED score was 3. After a multidisciplinary interrogation (neurologist, cardiologist, and radiologist), the cerebral stroke was attributed to thromboembolization secondary to AF and percutaneous LAA closure was planned. The patient's eligibility for treatment with the Amplatzer Amulet device was determined by cardiac computed tomography angiography and transesophageal echocardiography (TEE). The procedure was performed

Address for correspondence: Dr. Baris Kilicaslan, Department of Cardiology, S.B.U Izmir Tepecik EAH, Güney Mahallesi, 1140/1, Sokak No: 1, Yenişehir - Konak - Izmir, Turkey. E-mail: kilicaslanbaris@yahoo.com

This is an open access journal, and articles are distributed under the terms of the Creative Commons Attribution-NonCommercial-ShareAlike 4.0 License, which allows others to remix, tweak, and build upon the work non-commercially, as long as appropriate credit is given and the new creations are licensed under the identical terms.

For reprints contact: reprints@medknow.com

How to cite this article: Kilicaslan $\mathrm{B}$, Ozdogan $\mathrm{O}$, Cabuk $\mathrm{AK}$, Mutlu I. Thrombus on the device early after the procedure of the left atrial appendage closure with the amplatzer cardiac plug: Is something wrong with the procedure or the device?. Int J Cardiovasc Acad 2019;5:106-8. 
under general anesthesia, TEE, and fluoroscopic guidance. Transseptal access was achieved through the right femoral vein, using an SL1 sheath and a BRK-1 needle (St. Jude Medical, MN, USA). Intravenous heparin was given with a target activated clotting time $>300$ s. An extra-stiff wire was advanced through the upper pulmonary vein, and then, we inserted a $14 \mathrm{~F}$ guiding sheath through the wire. Then, we inserted a 22 no device through the catheter, and we pulled back all system from the pulmonary vein and directed to the LAA ostium. We rotated the system counter-clockwise and positioned it into the LAA. We checked its position with fluoroscopy, two-dimensional (2D) and three-dimensional (3D) TEE. After we released the device, we recognized a linear thrombus on the atrial side of the device with $2 \mathrm{D}$ and $3 \mathrm{D}$ echocardiography [Figures 1 and 2]. We pulled back the catheter and there was a big linear thrombus on the distal tip of the catheter [Figure 3]. The activated clotting time (ACT) was $290 \mathrm{~s}$ at that time. We injected $5000 \mathrm{U}$ unfractionated heparin (UFH) (intravenous) bolus after the procedure and continued with infusion at a rate of $1000 \mathrm{U} / \mathrm{h}$ for $48 \mathrm{~h}$ (dosage titrated according to activated partial thromboplastin time). After the infusion we performed TEE again and the thrombus had successfully been dissolved [Figure 4]. The patient was discharged with clopidogrel $75 \mathrm{mg} 1 \times 1$ and acetylsalicylic acid $100 \mathrm{mg} 1 \times 1$. One month after this procedure, TEE confirmed a good position of the device without thrombus [Figure 5].

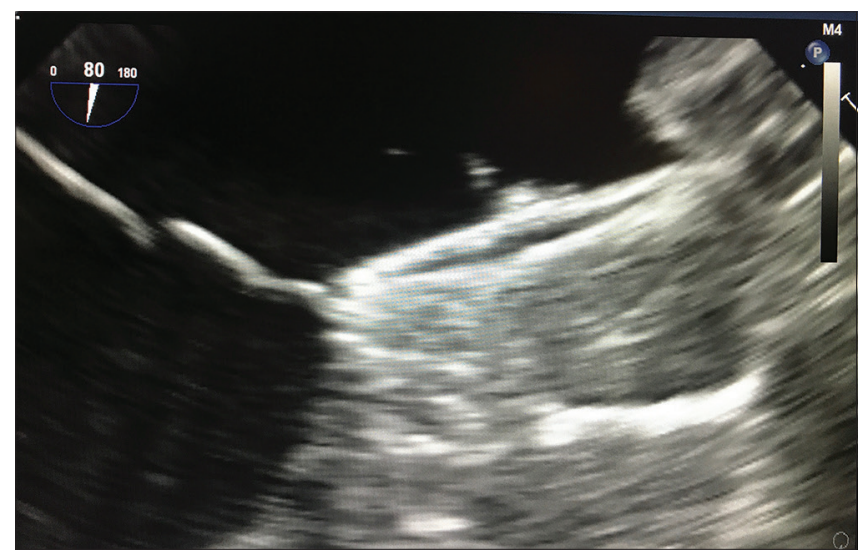

Figure 1: 2D views of the thrombus on the device

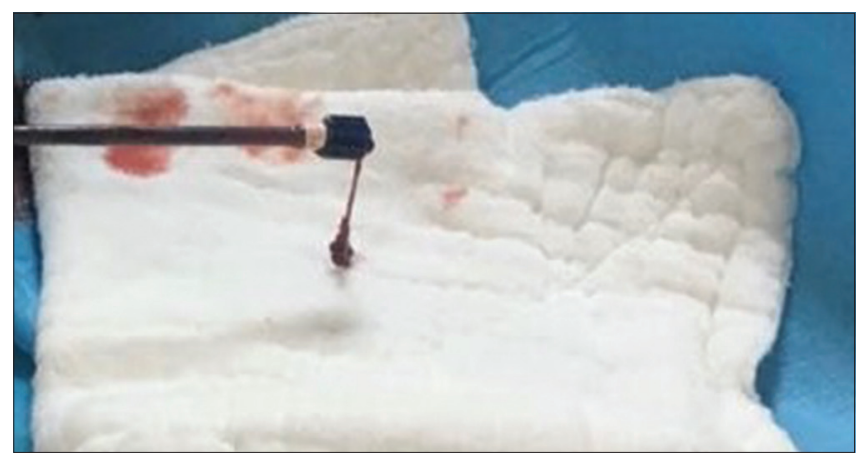

Figure 3: Thrombus on the tip of the catheter

\section{Discussion}

In the literature, thrombus formation on the device was demonstrated at the $1^{\text {st }}$ and $3^{\text {rd }}$ months after the procedure. ${ }^{[1,2]}$ However, there are no data about thrombus formation early after percutaneous LAA closure. Screw area of the device could be a progenitor of thrombus formation so we should be aware of giving effective dosage of UFH and obtaining at least 300 s of ACT level during operation. Wolff et al. ${ }^{[3]}$ recently reported two cases with early thrombus formation during Mitraclip procedure which were successfully treated with low dose thrombolytic infusion and with no embolic complication, but data about this kind of therapy particularly thrombi in the left side of the heart insufficient for us; hence, we choose the safer way.

\section{Conclusion}

This case demonstrates a management option of early thrombotic complication during LAA closure.

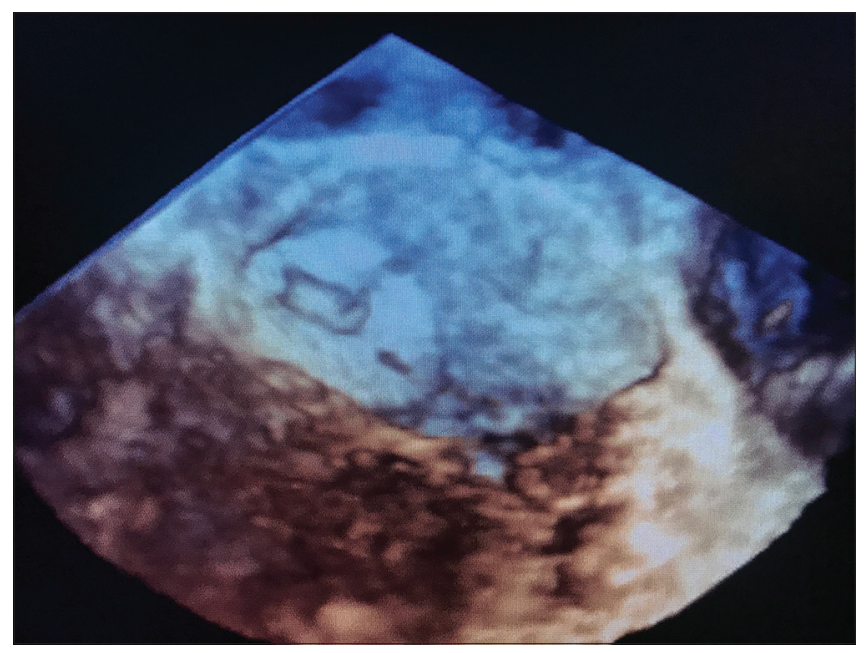

Figure 2: 3D views of the thrombus on the device

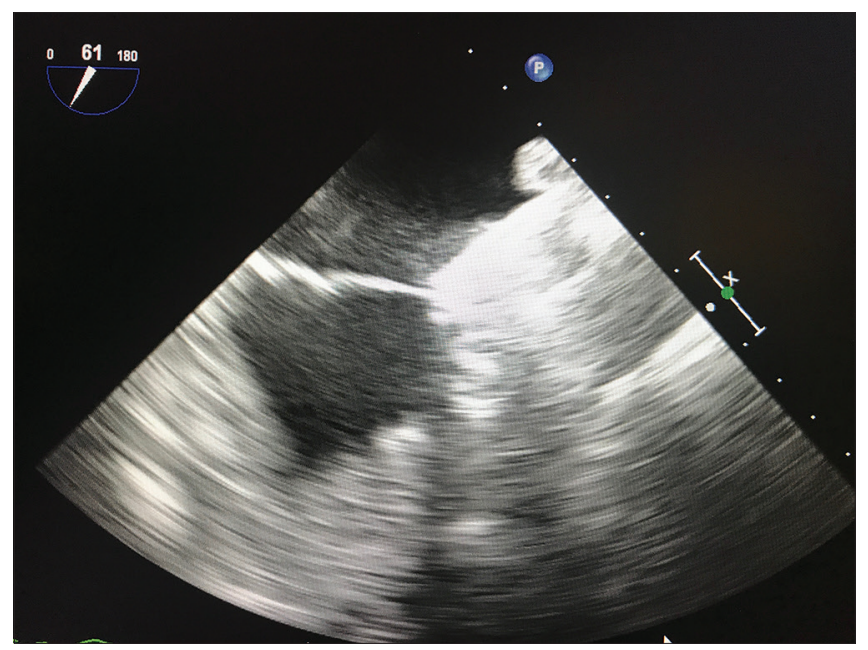

Figure 4: 2D view of the device after heparin infusion 


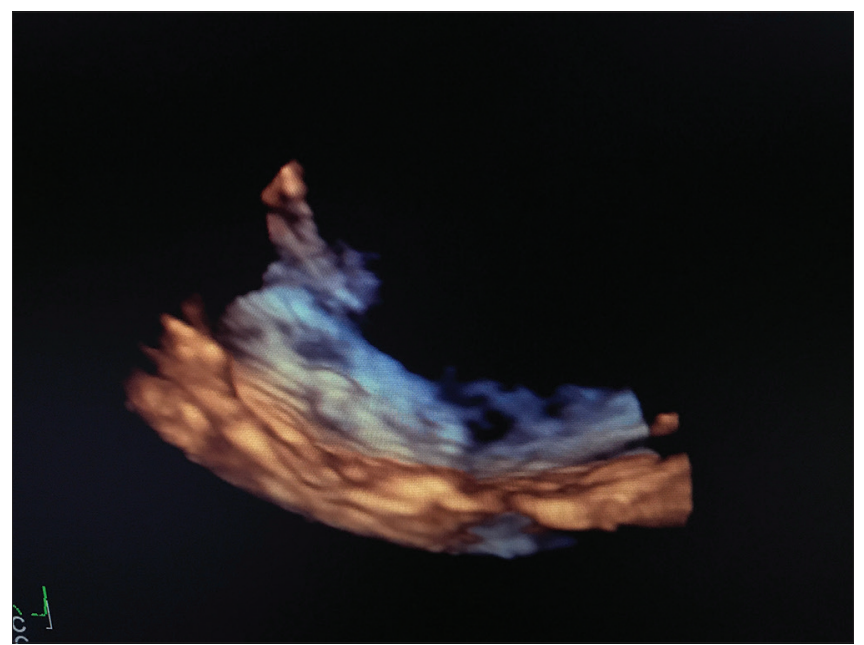

Figure 5: 3D view of the device after heparin infusion

\section{Declaration of patient consent}

The authors certify that they have obtained all appropriate patient consent forms. In the form the patient(s) has/have given his/her/their consent for his/her/their images and other clinical information to be reported in the journal. The patients understand that their names and initials will not be published and due efforts will be made to conceal their identity, but anonymity cannot be guaranteed.

\section{Financial support and sponsorship}

Nil.

\section{Conflicts of interest}

There are no conflicts of interest.

\section{RefEREnCes}

1. Sedaghat A, Schrickel JW, Andrié R, Schueler R, Nickenig G, Hammerstingl C, et al. Thrombus formation after left atrial appendage occlusion with the amplatzer amulet device. JACC Clin Electrophysiol 2017;3:71-5.

2. Landmesser U, Tondo C, Camm J, Diener HC, Paul V, Schmidt B, et al. Left atrial appendage occlusion with the AMPLATZER amulet device: One-year follow-up from the prospective global amulet observational registry. EuroIntervention 2018;14:e590-7.

3. Wolff G, Kelm M, Westenfeld R, Horn P. Low-dose thrombolysis for the management of left atrial thrombus formation during percutaneous mitral valve repair. JACC Cardiovasc Interv 2019;12:e9-10. 